\title{
BMJ Open Mental well-being of international migrants to Japan: a systematic review
}

\author{
Russell Miller, Yuri Tomita, Ken Ing Cherng Ong, Akira Shibanuma (D) , \\ Masamine Jimba
}

\begin{abstract}
To cite: Miller R, Tomita $\mathrm{Y}$, Ong KIC, et al. Mental well-being of international migrants to Japan: a systematic review. BMJ Open 2019;9:e029988. doi:10.1136/ bmjopen-2019-029988

- Prepublication history and additional material for this paper are available online. To view these files, please visit the journal online (http://dx.doi. org/10.1136/bmjopen-2019029988).
\end{abstract}

Received 21 February 2019 Revised 09 0ctober 2019 Accepted 09 October 2019

\section{Check for updates}

(C) Author(s) (or their employer(s)) 2019. Re-use permitted under CC BY-NC. No commercial re-use. See rights and permissions. Published by BMJ.

Community and Global Health, University of Tokyo, Bunkyo-ku, Japan

Correspondence to Professor Masamine Jimba; mjimba@m.u-tokyo.ac.jp

\section{ABSTRACT}

Background Migration is a stressful process of resettlement and acculturation that can often negatively impact the mental health of migrants. International migration to Japan, a country with dominant ethnic homogeneity, is growing steadily amid an ageing domestic population and severe labour shortages.

Objectives To identify the contemporary barriers to, and facilitators of, mental well-being among the migrant population in Japan.

Design Systematic review

Data sources PubMed, ProQuest, Web of Science, Ichushi and J-Stage

Eligibility criteria Research articles examining the mental well-being of international migrants in Japan that were published in English or Japanese between January 2000 and September 2018 were included.

Data extraction and synthesis Full texts of relevant articles were screened and references of the included studies were hand-searched for further admissible articles. Study characteristics, mental well-being facilitators and barriers, as well as policy recommendations were synthesised into categorical observations and were then thematically analysed.

Results Fifty-five studies (23 published in English), surveying a total of 8649 migrants, were identified. The most commonly studied migrant nationalities were Brazilian (36\%), followed by Chinese (27\%) and Filipino $(8 \%)$. Thematic analysis of barriers to mental well-being among migrants chiefly identified 'language difficulties', 'being female' and 'lack of social support', whereas the primary facilitators were 'social networks' followed by 'cultural identity'. Policy recommendations for authorities generally described more migrant support services and cross-cultural awareness among the Japanese public. Conclusion Access to social support networks of various types appears to be an influential factor affecting the mental well-being of international migrants in Japan. More research is necessary on how to promote such connections to foster a more inclusive and multicultural Japanese society amid rapid demographic change. PROSPERO registration number CRD42018108421.

\section{INTRODUCTION}

Global migration has increased markedly in recent decades and international migrants, in 2016, constituted $3.4 \%$ of the global population. ${ }^{1}$ International migrants are considered to be 'any person who lives temporarily or
Strengths and limitations of this study

- Our study is the first to comprehensively screen and synthesise available research, published both in Japanese and English, on the mental well-being of international migrants to Japan.

- Key findings were extracted and thematically analysed from relevant studies of diverse migrant populations in Japan evidencing the role of social support networks.

- The cross-sectional nature of the included studies limits their value in terms of generalisability and supporting causal effects.

- While English and Japanese databases were surveyed, grey literature was not comprehensively searched.

permanently in a country where he or she was not born, and has acquired some significant social ties to [their] new location'. ${ }^{2}$ Therefore migrants include non-indigenous people who are long-term immigrants, organisational expatriates, international students and migrant workers as well as forced migrants such as asylum seekers and refugees. While motivated by push and pull factors based on perceptions of opportunity, international migration has been well documented to be a stressful and multi-factorial process that can adversely affect health. ${ }^{2-4}$ The 'right to health' of migrants is enshrined in the Declaration of Alma-Ata (1978) and states receiving countries should take a comprehensive approach to healthcare of such sojourners beyond basic infectious disease control. ${ }^{5}$ Accordingly, migration is increasingly recognised as a structural socio-economic force that influences health outcomes as a social determinant of health, in general, and mental health, in particular. ${ }^{67}$

As the world's third largest economy, Japan was home to 2.2 million international migrants in October 2018. This figure represents about $2 \%$ of the national population and approximately 200000 foreign nationals were newly settled during that year. ${ }^{8}$ While the number of foreign residents settling in Japan continues 
to accelerate, the total population of Japan is predicted to decline by $31 \%$ from a peak of 126 million in 2016 to 87 million by $2060 .^{9}$ This demographic shift is a harbinger of the future as Japan is only the first nation in human history to experience population decline due to 'superageing'. Other high-income nations like South Korea, Germany and Italy are on a similar demographic trajectories and such changes will likely increase the proportion of young foreign national populations. ${ }^{10}$ However, unlike other high-income countries with a history of large-scale, institutional health research that includes non-citizens, ${ }^{11}$ in Japan, mainly exploratory research has been conducted on the health of migrants.

Facing a serious demographic challenge, the Japanese government has begun to publicly acknowledge the need for more foreign workers; however, structural issues continue to perturb the humanistic integration of international migrants. For example, a 2017 survey by the Ministry of Justice showed that $30 \%$ of foreign residents had experienced discrimination in Japan, with $40 \%$ having been rebuffed when seeking housing and $25 \%$ had been denied a job due to their nationality. ${ }^{12}$ Additionally, the Migration Integration Policy Index recently highlighted strict working visa requirements and a culture of overwork and harassment in Japan leading to occupational morbidity; ${ }^{13}$ such 'push' factors may impact the positive functioning of migrants trying to integrate into Japanese society.

The WHO defines mental health as, 'a state of wellbeing where every individual can realise his or her own potential, can cope with the normal stresses of life, can work productively and fruitfully, and is able to make a contribution to her or his community'. ${ }^{14}$ Mental wellbeing is a dual continuum that includes mental health and positive functioning open to sociocultural interpretation and includes concepts such as contentment, absence of negative life determinants, absence of disease or economic prosperity. ${ }^{14}$

Japan, as a host nation, has a unique cultural and linguistic context in which the mental well-being and related supports for migrants are likely impacted. To the best of our knowledge, there has been no synthesis of the literature on the mental health or well-being of international migrants to Japan. This systematic review was conducted in order to examine the social determinants of mental well-being among migrants. Our findings are a timely addition to the growing global health discipline of migrant health and may also provide authorities with an evidence base for further immigration reform and social design.

\section{METHODS}

\section{Patient and public involvement statement}

Patients and the public were not involved in the design or planning of this study.

\section{Study description}

This systematic review of observational studies was conducted in accordance with the 2009 Preferred
Reporting Items for Systematic Review and Meta-Analyses (PRISMA) reporting guidelines. ${ }^{15}$

\section{Inclusion and exclusion criteria}

Study selection was purposively designed to be broad in order to scope the progress of research assessing a heterogenous health concept in an equally diverse population. Migrant was defined in line with the Japanese government guidelines as a foreign national living in Japan for 3 months or more. ${ }^{8}$ Study inclusion criteria were: (1) published research assessing mental well-being among international migrants in Japan; (2) quantitative and/ or qualitative methodologies examining more than one migrant, including systematic reviews and (3) studies published in English or Japanese. Exclusion criteria were: (1) conference proceedings, expert opinions, single case reports or reviews; (2) analysis of international tourists and (3) studies published prior to January 2000. Mental well-being (including mental health outcomes such as depression, anxiety, resilience and so on) must have been assessed using a standardised research method including epidemiological surveys, interviews or medical records.

\section{SEARCH STRATEGY}

Electronic databases were searched for publications published between January 2000 and September 2018. Studies published before 2000 were excluded in order to better reflect the demographic characteristics of contemporary migrant populations in Japan which have changed dramatically over the past two decades. The following databases were queried: PubMed, UTokyo Resource Explorer (UTREE; includes ProQuest, SpringerLink, ScienceDirect) and Web of Science; as well as Japanese databases, Igaku-chuo-zasshi (Ichushi; https://search. jamas.or.jp/) and J-STAGE (https://www.jstage.jst.go. $\mathrm{jp} /$ ), each of which cite over 300000 articles per year from 2500 Japanese biomedical journals. The search was completed in September 2018, and the English as well as Japanese search terms are listed in table 1 . Both sets of search terms were used to query each database.

\section{Selection and retrieval process}

Based on the above selection criteria, two researchers (RM, YT) independently evaluated each title and abstract for inclusion. After removing duplicates, 1255 compiled titles were screened for relevance to the study topic, then study abstracts were read to confirm relevance. Any ambiguities throughout the selection process were discussed with a third researcher (KICO) and arbitrated through group consensus. After review, all but 80 titles were removed for full text review due to being inappropriate publication type, not on migrants in Japan or not examining an element of mental well-being. Full texts were reviewed to ensure the publications met all inclusion criteria. After this process, the remaining 55 full texts were included in data synthesis. References in these articles were hand-searched revealing 28 potentially useful 


\begin{tabular}{|c|c|}
\hline English & Japanese \\
\hline $\begin{array}{l}\text { "Mental health" OR } \\
\text { "Psychology" OR } \\
\text { "Mental well-being" } \\
\text { AND }\end{array}$ & $\begin{array}{l}\text { “精神保健" OR “メンタルヘル } \\
\text { ス" OR “心の健康" OR “精神衛 } \\
\text { 生" AND }\end{array}$ \\
\hline $\begin{array}{l}\text { "Migrant" OR } \\
\text { "Immigrant" OR } \\
\text { "Expatriate" OR } \\
\text { "Foreigner" OR } \\
\text { "Refugee" OR } \\
\text { "Foreign resident" OR } \\
\text { "International student" } \\
\text { AND }\end{array}$ & $\begin{array}{l}\text { “居住者" OR “駐在員” OR “労働 } \\
\text { 者" OR “移住者" OR “難民" OR } \\
\text { “留学生” } \\
\text { OR " 在留外国人" } \\
\text { AND }\end{array}$ \\
\hline “Japan” & $\begin{array}{l}\text { “在日" OR “日本における外国人" } \\
\text { OR “在留" }\end{array}$ \\
\hline
\end{tabular}

references. All full texts were located via the University of Tokyo library system or in case of difficult to locate manuscripts, by emailing the first author directly. Figure 1 is a PRISMA flow diagram of our screening process. ${ }^{15}$

\section{Data extraction}

A review library of included studies was made of PDF files using Mendeley referencing software. Data were extracted independently into Excel by the primary researchers (RM, YT). Extracted data (online supplementary table 1) were first author, year of publication, study design, study area (city or region), subject nationality (<4 largest groups are specified), number of subjects, mental health variable assessed, epidemiological tool employed, significant barriers as well as facilitators of mental well-being and subsequent policy recommendations. Non-significant factors presented by the study authors were not included in the extraction. Strategies and data presentation were discussed by researchers throughout the process to harmonise search and extraction strategies.

\section{Quality/bias assessment}

Study quality was assessed during data extraction using five specific criteria appropriate for the heterogeneity of the included studies which were adapted from the main guidelines of the Newcastle Ottawa Quality Assessment Scale for Cohort and Cross-Sectional Studies: selection,

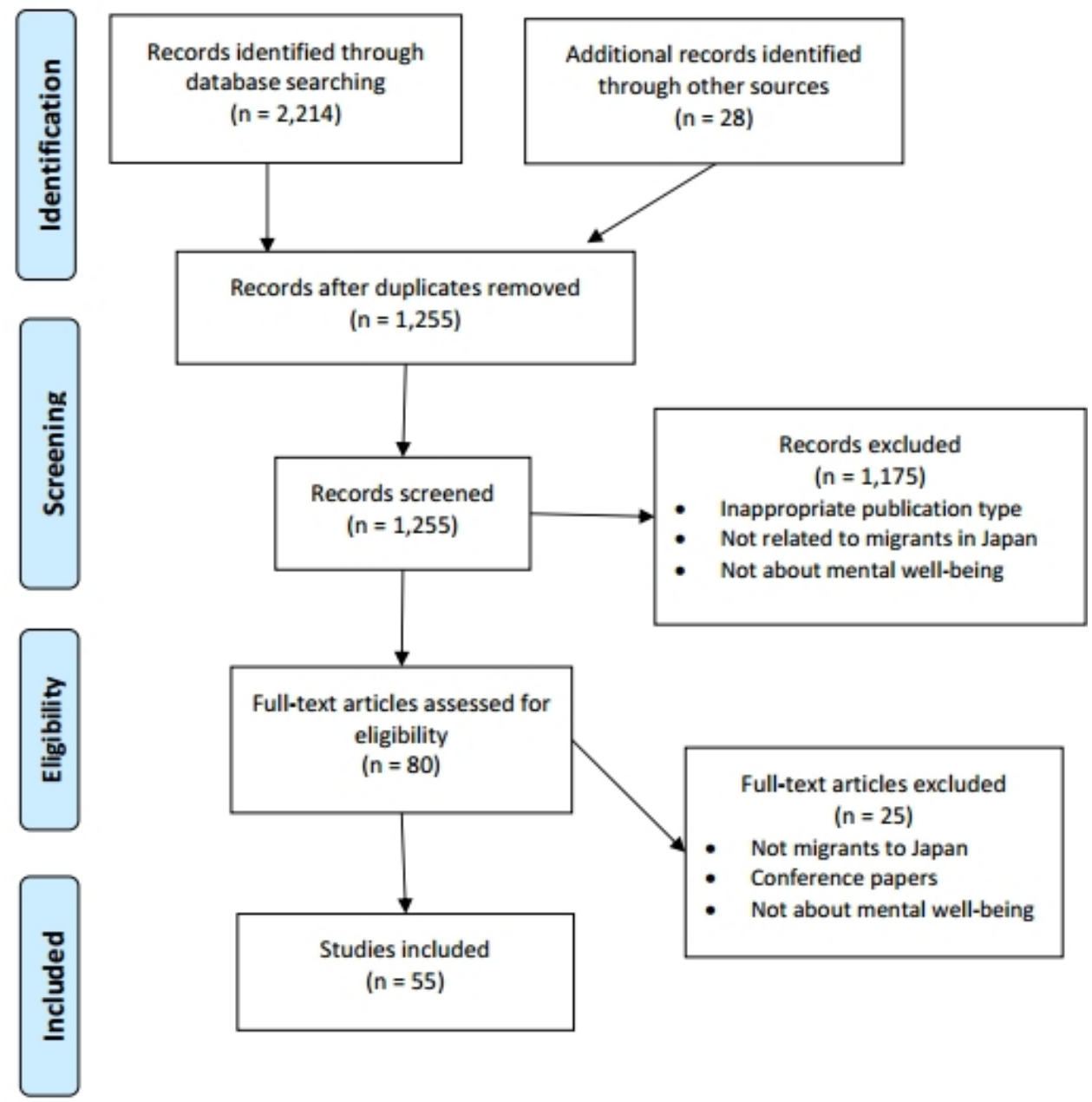

Figure 1 Flow diagram of studies that were identified using the search terms and strategy, articles screened for eligibility, included/excluded with reasons, following Preferred Reporting Items for Systematic Review and Meta-Analyses (PRISMA) guidelines. 
comparability and outcomes (online supplementary table 2 ). These criteria were as follows: consideration of premigration factors; consideration of postmigration factors; inclusion of a non-migrant comparison group; use of a valid measurement tool and justification of satisfactory sample size. A score of 1-5 were assigned to each study based on these criteria. Publications with scores 1-2 were labelled 'poor quality', 3 was considered 'average quality' and 4-5 were of 'good quality'. An experienced third reviewer was consulted (KICO) when assessing quality and potential publication bias.

\section{Data analysis}

In total, 55 full articles were included in our analysis. Due to the significant heterogeneity among study themes, populations and methodologies, a thematic synthesis was conducted instead of a meta-analysis. We did not predefine the way in which the relationships among concepts were evaluated within studies and accepted outcome measures based on the author's qualitative and/or quantitative assessment. Thematic analysis was used to group barriers and facilitators identified to have a significant association with their respective mental health variable of interest.

\section{RESULTS}

\section{Description of studies}

In total, 55 studies examining the mental well-being of international migrants in Japan were selected for this review (for a detailed selection flowchart see figure 1). There were 13 studies examining international university students studying in Japan and one of Brazilian middle school students (the youngest cohort assessed in this study). ${ }^{16-29}$ Eleven studies exclusively examined migrant workers $^{30-36}$ and four studies were on the mental wellbeing of economic partnership agreement care workers specifically. ${ }^{37-40}$ Two studies enrolled non-pregnant migrants ${ }^{414}$ and eight exclusively analysed mothers. ${ }^{43-50}$ The remaining nine studies were of general migrant populations of a single $(n=5)$ or various $(n=4)$ nationalities. ${ }^{51-59}$ There were 10 studies specifically examining Brazilians of Japanese descent, making them the most studied nation-specific migrant subgrouping in terms of mental well-being. ${ }^{60-70}$

In total, 8649 migrants were surveyed. This calculation excludes $>2000$ migrants reviewed in each of two systematic reviews. ${ }^{446}$ All subjects were recruited from the community or retrospectively from clinical records. On average three studies per year (range, 1-5) were consistently published on this topic since 2000. Of the included studies, 23 were published in English while the remaining were in Japanese. Their study designs were cross-sectional $(n=40$; one in four using a comparative population), qualitative $(n=7)$, case series $(n=3)$, mixed methods $(n=3)$ and systematic review $(n=2)$. Most studies were conducted in specific major metropolitan areas, such as Tokyo, Osaka, Sapporo and so on. As study location was sometimes anonymised, it was inferred that almost all studies were completed within central Japan in an urban setting. The number of subjects per study ranged from 3 to 1,252 , with a median size of 119. Importantly, a small number of migrants $(<75)$ were explicitly not enrolled in a health insurance plan; the only studies that listed this variable were those of Nepalese ${ }^{51}$ or Brazilians migrants. ${ }^{60-70}$

\section{Sample nationalities}

Of the migrants surveyed, $36 \%$ were Brazilian, $27 \%$ Chinese and $8 \%$ Filipino. Each nationality was exclusively studied in 14, 10 and 3 publications, respectively. The remaining 28 studies examined a mixed international migrant population. The four most numerous nationalities from each report were specifically extracted from a heterogeneous sample population, any remaining nationalities were identified as 'various' in online supplementary table 1 .

\section{Mental health variables and tools}

Almost every observational study employed some unvalidated survey questions in addition to at least one previously validated survey tool (in part or whole). Nonvalidated questions were marked as a 'questionnaire' tool in online supplementary table 1 . Additionally, the 33 epidemiological tools used among the studies to measure mental well-being are notedin the abbreviation legend in online supplementary table 3 .

\section{Thematic analysis}

More barriers than facilitators to mental well-being were cited among the included studies and multiple themes were often described in a single study.

\section{Barriers}

The most common barrier was trouble communicating in Japanese as 10 studies described such difficulty as negatively impacting mental health. These studies reported that language barriers created stress in managing daily life or trouble describing symptoms in a medical environment. The next most common barrier was a lack of support, either from teachers, ${ }^{16}$ employers, ${ }^{31}{ }^{40}$ family ${ }^{45}$ or healthcare professionals. ${ }^{43} 44$ These findings were very similar to a described lack of social networks (isolation or living alone) described in 11 studies. The third most common barrier to mental well-being was 'being female' cited in nine studies. Nine studies also mentioned various sources of stress, like acculturation, ${ }^{17}$ child-rearing $^{43}$ or finances. ${ }^{24}$ Occupational stress ${ }^{30} 313840$ and discrimination $^{2023} 3146$ were each mentioned in four studies, along with age over 30 years, ${ }^{34} 36$ and living in Japan for more than 1 year, ${ }^{1762}$ each described in two studies.

\section{Facilitators}

Social and support networks were found to be robust facilitators of mental well-being. These two concepts were mentioned 25 times as statistically significant outcomes. Some examples of such support were: in work or daily life, ${ }^{18}{ }^{38}$ living with family versus living 
alone ${ }^{4360}$ connecting with friends ${ }^{48} 69$ or maintaining connections with the migrant community. ${ }^{41}$ Occupational factors such as job satisfaction were noted nine times. Facilitators mentioned four times or fewer were: strong cultural identity, cultural adaptability, longer stay in Japan, coping skills, age under 30 years and Japanese fluency. Remarkably, 'being female' was found to be a facilitator in one study.

\section{Policy recommendations}

Two themes among policy recommendations were identified: calls for the creation of various support systems targeted at the migrant population by the government and calls for cross-cultural education of the public. Proposed support systems were educational $(n=7)$, general $(n=10)$, medical $(n=15)$ and occupational $(n=3)$. The types of cross-cultural education authors described: fostering awareness of migrant cultural backgrounds $(n=1)^{1845}$ and promoting a positive image of international migrants in mass media $(n=1)^{55}$.

\section{Quality/bias of studies}

Seventeen studies were found to be of high quality according to our criteria, while 33 were of average quality. This difference was due primarily to a failure to examine premigratory factors or employ a comparison group. Only four studies were considered of low quality and potential sources of bias mainly due to their unjustified small sample sizes. ${ }^{28} 445054$ Publication bias was assessed in cases of multiple publication or publishing in a suspected predatory journal; two studies were excluded for these reasons during review.

\section{DISCUSSION}

Overall a complex picture of this heterogeneous migrant population and factors impacting their mental well-being emerged after review. Thematic analysis demonstrated access to social support to be the most common determinant (barrier to or facilitator of) mental well-being among international migrants in Japan. Several other factors such as discrimination, language skills and length of stay were also found to impact migrant mental well-being. Based on these findings, authors often called for the creation of more migrant-focused support programmes and transcultural training for the Japanese public as a form of health promotion.

Psychosomatic symptoms, such as depression, among other mental disruptions were found to be significantly associated with a lack of support. In a few studies, for example, migrants without social support were reluctant to seek medical consultation perhaps due to language barriers or a lack of encouragement from others. ${ }^{46}$ Additionally, stress was reported to originate from many sources including: study, ${ }^{27}$ child rearing, ${ }^{48}$ family, ${ }^{45}$ occupation $^{46}$ and cultural adjustment. ${ }^{18} 5866$ Similarly, when migration has been examined more broadly as a social determinant of health has been shown to lead to isolation and distress if there is a deficiency in social connection in a postmigratory setting. ${ }^{71}$ Taken together, evidence from Japan suggests there is need for research into how migrants can identify social networks to support themselves as well as how host societies can foster such opportunities for better migrant integration.

Several included studies found that living in Japan for short periods was a barrier to mental well-being while longer stays were facilitators. For example, Brazilians living in Japan for limited periods for work $(<5$ years) were found to have a higher prevalence of mental disorders. ${ }^{606670}$ On the other hand, a study by Tsuji $e t$ al showed that Brazilians living in Japan for more than 5 years had fewer mental disorders. ${ }^{63}$ These findings support the assimilation theory of migration, where the length of residence in a host country and degree of proficiency in the host language are believed to positively influence the acculturation process within the first year of migration. ${ }^{72}$ New-comer migrants experience more mental disturbances due to culture shock and changes in daily life during this initial period. Visa status or stability was not mentioned as a significant factor for mental well-being even among studies including subjects with a variety of visas; broader comparative studies of this topic may be warranted.

Contrastingly, studies by $\mathrm{Qu}$ and $\mathrm{Li}$ as well as Tsuji et al found longer stays to be associated with worse well-being among different migrant populations. ${ }^{17} 68$ These findings support the cumulative disadvantage theory, which runs counter to the assimilation theory by suggesting that health-related disadvantages, such as persistent transcultural distress, increase with prolonged length of residence in a receiving country. ${ }^{72}$ While length of stay was often protective to migrant mental health in aggregate, similar to our results, a previous systematic review of migrant health also found such findings varied between migrant surveys in Canada. ${ }^{73}$

Discrimination is a well-studied part of the migrant experience. ${ }^{74}$ It was noted to be a factor associated with poorer mental well-being in several studies of various types of migrants. ${ }^{20} 233146$ For example, two studies reported negative mental effects for Chinese migrants who percieved exclusion by Japanese society but the studies disagreed as to whether mental well-being was positively affected by losing or maintaining a Chinese cultural identity. ${ }^{17} 18$ Interestingly, Asakura et al reasoned that Brazilians workers with Japanese language skills experienced discrimination because these workers could comprehend their status as an outsider in Japanese society more clearly. ${ }^{31}$ Examination of discrimination among skilled workers versus unskilled workers in Japan has also shown similar findings. ${ }^{75}$

The female gender and religiosity were found to be a barrier and facilitators of mental well-being, respectively. Ten studies concluded being female was a barrier to mental well-being; only one study suggested the female sex to be a facilitator of mental well-being. ${ }^{29}$ This outlier assessed support-seeking behaviours among students, perhaps suggesting that while 
female migrants to Japan experience more barriers to mental well-being, they are more likely to reach out for solutions than males; as has been shown previously in other immigrant populations. ${ }^{71}$ Previous migration studies have noted that female migrants experience significantly poorer mental wellbeing than the indigenous population. ${ }^{76}$ Additionally, several studies on Filipino, Brazilian and Muslim migrants established religiosity as a strong facilitator of mental well-being. ${ }^{32} 4143$ Cultural identity and religiosity as facilitators of mental wellbeing are consistent with previous research on cultural identity and religious beliefs among migrants. ${ }^{77}$

Most of the studies surveyed in this review had general recommendations for the Japanese government, health authorities or society at large. As might be expected, the most discussed recommendation was the implementation of various support systems ranging from Japanese language education, medical systems and personal support networks. Such supports, like the provision of translated information and consultation desks, may address barriers for migrants; encouragingly local authorities have or are planning to implement many such mechanisms. ${ }^{78}$ Notably absent from such government-backed systems, however, is support for a comprehensive medical interpretation system for healthcare institutions. ${ }^{79}$

A more novel suggestion raised by fewer publications was the importance of transcultural education about diversity or appreciation of different cultural backgrounds. This may be due in part to generalisation on the part of mass media and a general lack of awareness among the domestic population as the Japanese the word imin, immigrant, is generally only applied to low-skilled workers. ${ }^{80}$ More research about diversity education in Japan may help to address the social determinants of migrant mental health.

Robust sampling in migration research is understood to be difficult because migrant populations are inherently mobile and often prefer to remain unidentified. Thus, migrant research is chronically underfunded as research agencies are reluctant to award grants where rigorous methodology does not exist. ${ }^{3}$ Most studies on migrant mental well-being in Japan were community-based and used convenience or snowball sampling. Unsurprisingly, study populations were small, as half of studies enrolled less than 119 participants and only one publication included explicit sample size calculations. ${ }^{64}$ The study with by far the largest sample size, used government survey records from Hamamatsu, Ibaraki Prefecture, to study the social connectedness of 1252 Brazilians migrants. ${ }^{65}$ There were also four retrospective surveys of institutional medical records over several years identified by our study. ${ }^{27} 525460$ Taking into account the difficulty of sampling, samples were viewed as often justifiable to measure specific communities but representative cross-sections of entire migrant populations. In contrast, in their systematic review of immigrant women in the perinatal period, Kita $e t$ $a l$ surveyed more than 10 studies with large samples sizes that reviewed Japanese medical or governmental records. ${ }^{46}$ Improving the rigour in migrant health research in Japan will require more analyses of health records and secondary analysis of government administered surveys like the largescale surveys including migrants that are regularly carried out in the European Union. ${ }^{81}$

Next, the representativeness of migrant sampling, in terms of proportionality to the foreign community in Japan, was found to be skewed. The most populous migrant populations represented in our study were Brazilian $(37 \%)$, Chinese $(27 \%)$, Filipino $(8 \%)$ and Korean $(4 \%)$. It seems that Brazilian migrants and students, particularly Chinese students, have received more research attention in Japan. In reality, according to the Ministry of Justice, the four most populous migrant nationalities as of 2018, in descending order, were Chinese (29\%), Korean (18\%), Vietnamese $(10 \%)$ and Filipino $(10 \%){ }^{82}$ The Nepalese and Vietnamese populations in Japan have exploded since $2015,{ }^{8}$ and related research is only just appearing in the literature. Such research biases are remarkable and may carry across migrant studies in Japan and should be addressed for accurate scoping of migrant health. ${ }^{83}$

Migrants to Japan are relatively understudied compared with migrants in other high-income countries, especially in terms of mental health status. While this may be due to their comparatively low proportion in Japan (whereas $>12 \%$ in both Germany and UK), Japanese society is at a critical juncture with new visa categories launched in April 2019 dramatically increasing the number of foreign workers. ${ }^{84}$ Key health policy documents, such as the WHO Japan Health System Review, discuss health equity in depth but still only mention migrant health in passing. ${ }^{85}$ As it becomes clear that Japan perhaps needs international migrants perhaps more than the reverse, questions remain about whether Japanese social leaders are prepared to facilitate positive mental well-being to create a flourishing society together with migrants regardless of nationality and socioeconomic status.

There are limitations to this systematic review that should be noted. Most of the studies reviewed were cross-sectional and therefore could only describe correlation and not causation so the strength of actionable conclusions may be impacted. As a narrative approach was taken to data synthesis, all studies were given an equal weight regardless of size, level of significance and quality which could have given undue influence to the findings of four publications of lower quality. Heterogeneity testing or subgroup analysis of the surveyed literature was not done as part of a meta-analysis leaving the study qualitative in nature. Additionally, grey literature was not assessed, potentially leaving out valuable findings on this topic. The strengths of this systematic review are its comprehensive nature in terms of search strategy and data analysis as well as examining publications published in Japanese. In this way readers can better understand the diversity of the foreign resident population of Japan from the prospective of mental well-being.

\section{CONCLUSION}

The evidence gathered in this systematic review suggests the presence or absence of social support networks for migrants is the main determinant of mental well-being 
among foreign nationals living in Japan. While promotion of such ties is appropriate, the importance of promoting diversity awareness among healthcare professionals and society-at-large may be under-appreciated. Taken together, our results show that the mental well-being of migrants in Japan requires more investigation about how to best support the integration of international migrants in Japan to actionable government policy.

Contributors Conception and design: RM, YT, KICO and MJ; search strategy: RM and $\mathrm{YT}$; screening, extraction and quality assessment: $\mathrm{RM}$ and $\mathrm{YT}$; analysis and interpretation of data: RM, YT, KICO, AS and MJ; and drafting of the manuscript: RM. All authors critically reviewed and approved the manuscript.

Funding This study was supported by the University of Tokyo and the Ministry of Health, Labor and Welfare Research Grant for the Promotion of Health Administration (Kosei Rodo Gyosei Suishin Chosa Jigyohi): H30-Seisaku-Shitei-02.

\section{Competing interests None declared.}

Patient consent for publication Not required.

Ethics approval As primary human health data were not used in this research, ethical approval was not required.

Provenance and peer review Not commissioned; externally peer reviewed.

Data availability statement All data relevant to the study are included in the article or uploaded as supplementary information.

Open access This is an open access article distributed in accordance with the Creative Commons Attribution Non Commercial (CC BY-NC 4.0) license, which permits others to distribute, remix, adapt, build upon this work non-commercially, and license their derivative works on different terms, provided the original work is properly cited, appropriate credit is given, any changes made indicated, and the use is non-commercial. See: http://creativecommons.org/licenses/by-nc/4.0/.

\section{ORCID iD}

Akira Shibanuma http://orcid.org/0000-0003-2058-1722

\section{REFERENCES}

1 United Nations Educational, Scientific and Cultural Organization. Migrant/Migration [Internet], 2016. Available: http://www.unesco.org/ new/en/social-and-human-sciences/themes/international-migration/ glossary/migrant/ [Accessed 2018 Sept 1].

2 Abubakar I, Aldridge RW, Devakumar D, et al. The UCL-Lancet Commission on migration and health: the health of a world on the move. Lancet 2018;392:2606-54.

3 Renzaho AM. Globalisation, migration and health: challenges and opportunities. 1st ed. London: Imperial College Press, 2016.

4 Virupaksha HG, Kumar A, Nirmala BP. Migration and mental health: an interface. J Natural Sci Bio Med 2014;5:233-9.

5 International Organization for Migration. World Migration Report 2018 [Internet], 2018. Available: https://www.iom.int/wmr/world-migrationreport-2018 [Accessed 2018 Dec 3].

6 Castañeda H, Holmes SM, Madrigal DS, et al. Immigration as a social determinant of health. Annu Rev Public Health 2015;36:375-92.10.1146/annurev-publhealth-032013-182419

7 Salami B, Yaskina M, Hegadoren K, et al. Migration and social determinants of mental health: results from the Canadian health measures survey. Can J Public Health 2017;108:362-7.

8 Ministry of Justice. Foreign National Residents by Nationality [Internet], 2019. Available: http://www.stat.go.jp/english/data/ nenkan/68nenkan/1431-02.html [Accessed 2019 Feb 2].

9 Ministry of Internal Affairs and Communications, Statistics Bureau. Future Population (2016 to 2110) [XLS], 2017. Available: http://www. stat.go.jp/english/data/jinsui/2.html [Accessed 2018 Dec 15].

10 Parsons AJQ, Gilmour S. An evaluation of fertility- and migrationbased policy responses to Japan's ageing population. PLoS One 2018;13:e0209285.

11 Eikemo TA, Bambra C, Huijts T, et al. The first pan-European sociological health inequalities survey of the general population: the European social survey rotating module on the social determinants of health. Euro Socio Rev 2017;33:137-53.

12 Ministry of Justice. Analytical report of the foreign residents survey [Internet], 2017. Available: http://www.moj.go.jp/content/001249011. pdf [Accessed 2018 Dec 25].
13 Migration Integration Policy Index. Japan: Key Findings [Internet], 2015. Available: http://www.mipex.eu/japan [Accessed 2019 Jan 1].

14 World Health Organization. Mental health: a state of well-being [Internet], 2014. Available: http://who.int/features/factfiles/mental_ health/en/ [Accessed 2018 Sept 1].

15 Moher D, Liberati A, Tetzlaff J, et al. Preferred reporting items for systematic reviews and meta-analyses: the PRISMA statement. PLoS Med 2009;6:e1000097.

16 Kakefuda A. A study into mental health of Japanese-Brazilian students [in Japanese]. J Psyche Cultur 2004;3:67-72.

17 Qu X, Li L. Acculturation and GHQ-30 of Chinese students in Japan. Psychol Stud 2013;59:145-50.

18 Sun Y. Chinese students in Japan: the mediator and the moderator between their personality and mental health. Int J Psychol 2013;48:215-23.

19 Eskanadrieh S, Liu Y, Yamashina H, et al. Depressive symptoms among international university students in northern Japan: Prevalence and associated factors [in Japanese]. Int Health 2012;27:165-70.

20 Murphy-Shigematsu S. Psychological barriers for international students in Japan. Int J Adv Counsell 2002;24:19-30.

21 Guo Y, Li Y, Ito N. Exploring the predicted effect of social networking site use on perceived social capital and psychological well-being of Chinese international students in Japan. Cyberpsychol Behav Soc Netw 2013;1:1-7.

22 Ozeki N, Knowles A, Ushijima H, et al. Analysis of transcultural stress factors and the mental well-being of foreign Chinesespeaking students in Aomori. J Aomori Univ Health Welf 2006;7:8-16.

23 Zheng G, Jimba M, Wakai S. Exploratory study on psychosocial impact of the severe acute respiratory syndrome (SARS) outbreak on Chinese students living in Japan. Asia Pac J Public Health 2005;17:124-9.

24 Kono K, Eskandarieh S, Obayashi Y, et al. Mental health and its associated variables among international students at a Japanese university: with special reference to their financial status. J Immigr Minor Health 2015;17:1654-9.

25 MA BIN, Ma B. The relationship between mental health status and psychosociological factors among Chinese postgraduate students in Japan. Juntendo Med J 2007;53:200-10.

26 Matsuda T, Tsuda A, Deng K. Relationship between stage of change for stress management behavior and mental health among Chinese international students in Japan. Kurume Univ Psychol Res 2013;12:44--9.

27 Hori T, Tachikawa H, Ishi T, et al. An analysis of mental disorders of international students visiting the mental health service at Tsukuba University Health Center [in Japanese]. Psych Neuro Jpn 2012;114:3-12.

28 Wang F, Kyoko Y. Chinese self-sponsored overseas students' change tendency in mental health and relevant reasons [in Japanese]. Psychol Rep Sophia Univ 2009;33:109-25.

29 Mizuno $\mathrm{H}$, Ishikuma T, Toshinori I. Relation of sociological and psychological factors to preferences among professional helpers by Asian international students in Japan. Jpn J Edu Psychol 2000;48:165-73.

30 Lee G. Job stress and mental health among high-skilled foreign workers (HFWs) in Japan: comparative analysis between HFWs and Japanese workers [in Japanese]. Stress Sci Res 2015;30:90-101.

31 Asakura T, Gee GC, Nakayama K, et al. Returning to the "homeland": work-related ethnic discrimination and the health of Japanese Brazilians in Japan. Am J Public Health 2008;98:743-50.

32 Onishi A, Murphy-Shigematsu S. Identity narratives of Muslim foreign workers in Japan. J Community Appl Soc Psychol 2003;13:224-39.

33 Ohara-Hirano Y. Cognitive life strains and family relationships of Filipino migrant workers in Japan. Asian and Pacific Migration Journal 2000;9:365-74.

34 Date Y, Abe Y, Aoyagi K, et al. Depressive symptoms in Chinese factory workers in Nagasaki, Japan. Ind Health 2009;47:376-82.

35 Ohara-Hirano Y. The implication of socio-economic strain in depression of overseas Filipino workers [in Japanese]. Jpn Bull Soc Psychiatry 2005;14:134-45.

36 Cho Y. Suicide prevention for foreign workers and trainees [in Japanese]. Jpn J Occup Ment Health 2005;13:4-15.

37 Ohara-Hirano Y. The mental health status of Indonesian candidates leaving for Japan under the Japan-Indonesia economic partnership agreement: after the great East Japan earthquake. Int J Jpn Sociol 2012;21:37-45.

38 Nugraha S, Ohara-Hirano Y. The mental health predictors of Indonesian EPA nurses and certified care worker candidates in Japan. Jpn Psychol Res 2016;58:85-96. 
39 Sato F, Hayakawa K, Kamide K. Investigation of mental health in Indonesian health workers immigrating to Japan under the economic partnership agreement. Nurs Health Sci 2016;18:342-9.

40 Yamamoto T, Mizukami K. Occupational stress among nurses working in Japan through the economic partnership agreement (EPA) [in Japanese]. J Gen Fam Med 2018;41:38-44.

41 Paillard-Borg S, Hallberg D. The other side of the mirror: an analytic Journalistic approach to the subjective well-being of Filipino women migrant workers in Japan. SAGE Open 2018:8:215824401875728-10.

42 Shah R, Kiriya J, Shibanuma A, et al. Use of modern contraceptive methods and its association with QOL among Nepalese female migrants living in Japan. PLoS One 2018;13:e0197243.

43 Martinez M, Hatashita $\mathrm{H}$, Suzuki $\mathrm{H}$, et al. Socio-cultural factors affecting the health of pregnant and puerperal Brazilian women in Japan [in Japanese]. J Int Health 2017;32:69-81.

44 Kawasaki C. Birth and child-rearing experiences of immigrant women in Japan and their support needs: a literature review [in Japanese]. Jpn Community Health Nurs 2014;16:90-7.

45 Jin Q, Mori E, Sakajo A. Risk factors, cross-cultural stressors and postpartum depression among immigrant Chinese women in Japan. Int J Nurs Pract 2016;22:38-47.

46 Kita S, Minatani M, Hikita N, et al. A systematic review of the physical, mental, social, and economic problems of immigrant women in the perinatal period in Japan. $J$ Immigr Minor Health 2015;17:1863-81.

47 Imai S, Kita S, Tobe $\mathrm{H}$, et al. Postpartum depressive symptoms and their association with social support among foreign mothers in Japan at 3 to 4 months postpartum. Int J Nurs Pract 2017;23:e12570-9.

48 Bunketsu Y, Emori Y. Parenting stress of Chinese mothers living in Japan. [in Japanese]. J Gen Fam Med 2010;33:101-9.

49 Korean SY. Chinese, Brazilian mothers' child rearing stress in Japan [in Japanese]. Jpn J Matern Health 2002;43:530-40.

50 Fujiwara Y, Horiuchi S. Immigrant women giving birth in Japan: experience of loneliness and isolation [in Japanese]. J Hum Care Stud 2007;8:38-50.

51 Shakya P, Tanaka M, Shibanuma A, et al. Nepalese migrants in Japan: what is holding them back in getting access to healthcare? PLoS One 2018;13:e0203645.

52 Koyama A, Okumi H, Matsuoka H, et al. The physical and psychological problems of immigrants to Japan who require psychosomatic care: a retrospective observation study. Biopsychosoc Med 2016;10:35-7.

53 Moon J-S, Mikami H. Difference in subjective well-being between ethnic Korean and Japanese elderly residents in an urban community in Japan. Geriatr Gerontol Int 2007;7:371-9.

54 Koyama A, Niki M, Matsuoka $\mathrm{H}$, et al. Psychological problems for non-Japanese speaking patients in Japan. $J$ Travel Med 2012;19:324-6.

55 Ichikawa M, Nakahara S, Wakai S. Effect of post-migration detention on mental health among Afghan asylum seekers in Japan. Aust N Z J Psychiatry 2006;40:341-6.

56 Itoi Y. Acculturative stress among Cambodian living in Japan [in Japanese]. Jpn J Hum Sci Health-Soc Serv 2007;35:51-8.

57 Fukaya $\mathrm{H}$. Acculturative stress and depression among foreigners in Japan [in Japanese]. Jpn Bull Soc Psychiatry 2002;11:11-19.

58 Ohara-Hirano Y. Study on depression experienced by foreign residents in Kyushu area [in Japanese]. Mem Kyushu Univ Sch Health Sci 2001;28:129-37.

59 Lee C-ho, Min S-kil, Jeon W-taek, et al. Mental health and quality of life of North Korean defectors living in Japan. Asian J Psychiatr 2009;2:95-9.

60 Miyasaka LS, Canasiro S, Abe Y, et al. Migration and mental health: Japanese Brazilians in Japan and in Brazil. J Bras Psiquiatr 2007:56:48-52

61 Kondo S, Otsuka K, Sawaguchi GT, et al. Mental health status of Japanese-Brazilian children in Japan and Brazil. Psychiatry Clin Neurosci 2011;65:226-32.

62 Asakura T, Murata AK. Demography, immigration background, difficulties with living in Japan, and psychological distress among Japanese Brazilians in Japan. J Immigr Minor Health 2006;8:325-38.
63 Tsuji K, Miyasaka LS, Otsuka K, et al. Panic disorder cases in Japanese-Brazilians in Japan: their ethnic and cultural confusion. Psychiatry Clin Neurosci 2001;55:127-30.

64 Miyasaka LS, Otsuka K, Tsuji K, et al. Mental health of two communities of Japanese-Brazilians: a comparative study in Japan and in Brazil. Psychiatry Clin Neurosci 2002;56:55-64.

65 Takenoshita $\mathrm{H}$. Social capital and mental health among Brazilian immigrants in Japan. International Journal of Japanese Sociology 2015;24:48-64.

66 Honda G, Otuka K, Kuniaki Y, et al. Psycho-social risk factors for mental disorder among Japanese-Brazilian in Japan [in Japanese]. Jpn Bull Soc Psychiatry 2005;14:45-54

67 Tsuji K, Miyasaka L, Otsuka K. Depression among immigrants to Japan - A mental health survey of Japanese-Brazilians [in Japanese]. Jpn Bull Soc Psychiatry 2000;9:163-70.

68 Tsuji K, Miyasaka L, Otsuka K, et al. Influence of relationship between duration of residence in Japan and degree of adaptation on the mental health status of Japanese-Brazilian immigrants [in Japanese]. Jpn Bull Soc Psychiatry 2002;10:253-60.

69 Asakura T. The association between acculturation to Japan life and psycho-somatic distress among Japanese-Brazilian students [in Japanese]. Jpn J Sch Health 2005;46:628-47.

70 Otsuka K, Miyasaka L, Honda G, et al. Cultural adaptation and mental health among Brazilians of Japanese descent living in Japan [in Japanese]. Jpn Bull Soc Psychiatry 2001;10:149-58.

71 MÁ S-F, del Otero-Sanz L, Martín-Madrazo C, et al. The relationship between social support and self-reported health status in immigrants: an adjusted analysis in the Madrid cross sectional study. BMC Fam Pract 2011;12.

72 Dhadda A, Greene G. 'The healthy migrant effect' for mental health in England: Propensity-score matched analysis using the empiric survey. J Immigr Minor Health 2018;20:799-808.

73 Vang ZM, Sigouin J, Flenon A, et al. Are immigrants healthier than native-born Canadians? A systematic review of the healthy immigrant effect in Canada. Ethn Health 2017;22:209-41.

74 Ibañez GE, Dillon F, Sanchez M, et al. Changes in family cohesion and acculturative stress among recent Latino immigrants. J Ethn Cult Divers Soc Work 2015;24:219-34.

75 Shun G. Are the consequences of experiencing discrimination the same for immigrants of differing socio-economic status in Japan? Int Migr 2017;56:37-55.

76 Gkiouleka A, Avrami L, Kostaki A, et al. Depressive symptoms among migrants and non-migrants in Europe. Eur $J$ Public Health 2018;1:54-60.

77 Bhugra D, Becker MA. Migration, cultural bereavement and cultural identity. World Psychiatry 2005;4:18-24.

78 Japan approves 126 measures to attract more foreign workers. Nikkei Asian review, 2018. Available: https://asia.nikkei.com/ Spotlight/Japan-Immigration/Japan-approves-126-measures-toattract-more-foreign-workers

79 Hamai T, Nagata A, Nishikawa H. The need for medical interpreters: a questionnaire survey of municipal hospitals in Japan [in Japanese]. Jpn J Public Health 2017;64:672-83.

80 Leppold C, Ozaki A, Shimada Y, et al. Defining and acting on globa health: the case of Japan and the refugee crisis. Int $J$ Health Policy Manag 2016;5:457-60.

81 European Union, Migrant Policy Group. Migrant Health Across Europe. [Internet], 2018. Available: https://ec.europa.eu/migrantintegration/feature/migrant-health-across-europe [Accessed 2018 Dec 15].

82 Ministry of Justice. Statistics on the foreigners registered in Japan [XLS], 2017. Available: www.ipss.go.jp/p-info/eps2017/PSJ2017-10. Xls [Accessed 2018 Nov 24].

83 Bhopal R, Rafnsson S. Global inequalities in assessment of migrant and ethnic variations in health. Public Health 2012;126:241-4.

84 Nikkei Asian Review. Japan enacts divisive foreign worker bill to ease labor shortage, 2018. Available: https://asia.nikkei.com/Spotlight/ Japan-Immigration/Japan-enacts-divisive-foreign-worker-bill-toease-labor-shortage

85 World Health Organization. Japan: Health System Review [Internet], 2018. Available: http://apps.who.int/iris/bitstream/handle/10665/ 259941/9789290226260-eng.pdf;jsessionid=5E8D4C6125118E61 3132CA81B02306D7? sequence $=1$ [Accessed 2018 Nov 25]. 